\title{
Temperature Creep and the Relationship Between Creep and
}

\author{
Melting by Use of High Pressure as a Variable
}

\author{
DE-FG03-88ER45360
}

\author{
University of California \\ Davis, CA 95616
}

\section{PROGRESS REPORT}

\section{APPARATUS DEVELOPMENT}

\section{Experimental Geometry}

Precise stress measurement at high pressure requires a very accurate knowledge of friction on the deformation piston (Fig. 1) because stress is measured external to the high pressure volume. We have developed a high pressure assembly that utilizes molten alkali halides as the confining medium in the specimen chamber (Green and Borch, 1989; 1990). This fluid medium of low viscosity surrounding the specimen provides the necessary internal environment for low friction. When we began the experiments of this project, however, the demands on the machinery were much greater than previously because precise measurement of low stresses was much more critical for the success of the research. In particular, in this work it is necessary to be able to measure very small changes in load. We found it necessary to stiffen and increase the mechanical efficiency of the drive system by removing the thrust bearing of the original design and replacing it with a moving ball nut similar to that of commercial one-atmosphere apparatus with mechanical drives. Although the molten salt eliminates friction in the immediate vicinity of the sample, friction on the moving piston where it enters the high pressure chamber and in the colder regions of the assembly is dependant on pressure, temperature and piston velocity and location. As a consequence, experiments must be conducted in compression and in constant strain-rate mode and the piston must be withdrawn from contact with the specimen for any change of conditons so that friction can be remeasured for each cycle. The latter operation allows friction to be measured precisely by determining the time-independent force required to advance the piston whose tip is surrounded by liquid as it approaches the specimen. To ensure comparability between the high pressure experiments and those at one atmosphere, we conduct all experiments at constant strain rate in axial compression.

\section{Specimen Environment}

Nickel is highly soluble at high temperature in the $\mathrm{NaCl}-\mathrm{KCl}$ salts used in our original liquid cell design. Our first task, therefore, was to establish an appropriate molten salt that would not significantly dissolve the specimens. We have found that salts of the quaternary $\mathrm{Ba} \mathrm{Ca} N \mathrm{Na}-\mathrm{K}$ - 
$\mathrm{Cl}$ system are ideal for the purpose. These heat-treat salts melt at very low temperatures (the eutectic occurs at $\sim 700 \mathrm{~K}$ at one atmosphere), yet appropriately chosen compositions dissolve negligible amounts of $\mathrm{Ni}$ even at $1550 \mathrm{~K}$. These salts also prevent oxidation of Ni. Therefore, rather than controlling the oxygen fugacity in the 1-atmosphere experiments by introducing an appropriate gas mixture, we have constructed a salt-containment vessel to immerse the specimens in the quaternary salt mixture, thereby making the chemical environment in those experiments identical to that of the high pressure experiments. Fig. 2 shows undeformed and deformed specimens from each apparatus. The only effect the salts have had is to remove damaged material left on the specimen surfaces during machining, slightly accentuating the grooves produced by machining.

Silicon is similarly insoluble in the quaternary salt system, but its much greater sensitivity to oxidation requir:s that the metal sleeve of the high pressure assembly (Fig. 1) be made of a macerial whose metal-oxide reaction buffers the oxygen fugacity to values lower than the $\mathrm{Si}-\mathrm{SiO}_{2}$ reaction. Both titanium and molybdenum can serve this purpose, but we have found that $\mathrm{Ti}$ induces disastrous reactions with various ceramic components of the assembly. The only adverse reaction induced in a Mo-buffered environment is leaching of the binder from the $\mathrm{Al}_{2} \mathrm{O}_{3}$ deformation pistons, inducing them to fail under differential stresses of $\sim 200 \mathrm{MPa}$. This is a serious problem for experiments on strong materials that require low oxygen fugacity and has not yet been solved. As discussed below, we have sidestepped this problem for Si by encapsulation, but that solution introduces other problems such as alloying and eutectic melting of the Si and capsule.

\section{Experimental Procedures}

All components of the high pressure assembly (Fig. 1) are solid at low temperature, hence accomplishing pressurization without damage to the specimen (or furnace) is not trivial. Before this research project began we had experience only with silicates which are very strong and reasonably tough. $\mathrm{Ni}$, on the other hand is much weaker and ductile even at room temperature and $\mathrm{Si}$ is extremely brittle. Raising the temperature above the melting temperature of the confining salt before pressurization was not a satisfactory solution because differential compaction of the remaining parts during pressurization invariably led to damage of the furnace, breakage of the thermocouples or misalignment of the specimen. These problems proved to be more difficult to solve than we anticipated and many experiments were lost and others produced unusable data until an appropriate specimen preparation and pressurization procedure was developed. To minimize misalignment of the specimen and damage to the thermocouples or the furnace due to compaction during pressurization, it was found necessary to minimize the free space in the high pressure assembly. We developed a procedure whereby all parts outside the furnace are machined to high tolerances and in which the salt inside the furnace (the salt that melts during the experiment) is melted with a welding torch and cast around the specimen. This has the double advantage of reducing porosity to zero in the immediate vicinity of the specimen and encasing the specimen in a strong sheath for the initial, cold, stage of pressurization. The latter is a happy consequence of the considerable strength of the $\mathrm{BaCl}$ component of the salt. After slow pressurization $(-500 \mathrm{MPa} / \mathrm{hr})$ to $\sim 800 \mathrm{MPa}$ at room temperature, the rest of the pressurization is under conditions where the salt is hot but still solid. Subsequent temperature increase to the conditions of experimentation or preannealing is accomplished by ramping at $1 \mathrm{~K} / \mathrm{hr}$. For delicate materials such as $\mathrm{Si}$, which is extremely brittle, or for single crystals intended for analysis by spectroscopy, depressurization and cooling can be similarly slow, with the temperature kept above the solidus of the salt until the last $100-200 \mathrm{MPa}$ when furnace contact is often lost. Alternatively, when preservation of the microstructure existing at the end of the experiment is of primary importance, the temperature can be quenched several hundred Kelvins in a few seconds, but cracking of brittle materials is to be expected. These procedures are now routine with the new apparatus that has automated pumping and temperature ramping capabilites. 


\section{GPa Apparatus}

Only the frame to the $5 \mathrm{GPa}$ apparatus existed when this research program began. Details of its design have been steadily modified to accomodate the new procedures we have developed for pressurization and experimentation. For example, we incorporated the new drive system design developed for the $3 \mathrm{GPa}$ apparatus during this project. The new apparatus is now operational for experiments up to $2.5-3 \mathrm{GPa}$, using the pressure vessels designed for the older machine. The 5 GPa pressure vessel has been constructed but the special cooling system for that vessel is not yet complete. An hydraulic drive also is being designed for this apparatus, but it currently is operating satisfactorily with its mechanical drive and stepping motor (Fig. 3).

\section{NICKEL}

\section{One-Atmosphere Experiments}

Experiments at 1-atmosphere are conducted in AKM's laboratory on a modified MTS apparatus (model 311.11) with a servo-hydraulic drive and upgraded data collection system. This phase of the project only began in Summer, 1989 when Mr. Seamus Meagher, a graduate student in Materials Science joined the project. To allow for direct comparison with the high pressure results, all specimens are immersed in the molten quaternary salt and experiments are conducted in axial compression at constant strain rates between $10^{-5.0}$ and $10^{-2.5} \mathrm{sec}^{-1}$. Specimens are Ni 270 , cold-worked to $35 \%$, purchased in rod form and machined to right cylinders $1.27 \mathrm{~cm}$ diameter by $1.91 \mathrm{~cm}$ long. The stress is accurate to $\pm 0.2 \mathrm{MPa}$; the temperature is monitored with a Type $\mathrm{B}$ thermocouple and typically varies $\pm 5 \mathrm{~K}$ over the course of an experiment. To avoid thermal shock damage to the $\mathrm{Al}_{2} \mathrm{O}_{3}$ compression rods, the temperature is ramped between room temperature and the experimental temperature at $1.5 \mathrm{~K} / \mathrm{min}$ both before and after deformation. This thermal path serves to recrystallize the specimens (Fig. 2) and completely remove the initial cold-worked dislocation substructure (Fig. 4). Specimens deformed immediately after attaining the experimental temperature show a finer grain size after deformation than similar specimens subjected to an additional isothermal $1550 \mathrm{~K}$ annneal before deformation but both are in the grain-size insensitive regime, hence, they exhibit the same steady-state flow stress. Representative stress-strain curves are shown in Fig 5. All experiments showed stress oscillations of about 3-4 MPa, independent of temperature. Many but not all specimens showed damping of the oscillations with increased strain at constant temperature. We attribute the oscillations to periodic recrystallization and consequent softening that has been reported previously for Ni (Luton and Sellars, 1969). Of particular interest was the observation that $\mathbf{n}$ decreases monotonically with increasing temperature (Fig. 6), whereas the activation energy remains constant and equal to that for self-diffusion (Fig. 7). Except for the decrease of $\mathbf{n}$ at very high temperature, our results are in excellent agreement with previous work. The decrease in $\mathbf{n}$ is consistent with the recent experimental work in other systems and with theory (discussed above) and will be investigated further in the coming months.

\section{High Pressure Experiments}

As indicated above, our earliest experiments on $\mathrm{Ni}$ illuminated problems in the upper part of the apparatus and experimentation was delayed while we redesigned the mechanism whereby rotary motion of the motor and gear train are converted into longitudinal motion of the piston. After completion of this modification, we established that the results from our apparatus are in agreement with those of machinery in which the pressure is applied by pressurized gas and the force on the specimen is measured internal to the pressure chamber (Borch et al., 1989). This step was of critical importance because never before had it been possible to compare the "solidmedium" apparatus with a gas-medium apparatus at low stresses and demonstrate that they profuce comparable measurements. 
As we collected more high pressure data, however, the systematics of the results were not consistent with previous work at one atmosphere. For example, we found $\mathbf{n}<4$ rather than $\mathbf{n} \sim 7$ as reported by previous workers (e.g. Karashima et al., 1969). Moreover, as we amassed data at 1 atmosphere, we also found $\mathbf{n} \sim 7$ and strengths lower than those measured at pressure. Both sets of experiments were conducted in compression in the liquid salt bath. The only difference was that to avoid cracking the $\mathrm{Al}_{2} \mathrm{O}_{3}$ compression rods in the 1-atmosphere apparatus, temperature had to be ramped up very slowly, whereas the time at temperature in the high pressure apparatus had been minimized because of short furnace life at high temperature. Examination of this problem determined that it was the cause of the discrepancy; the cold-worked structure of the starting material was not being completely removed in the high pressure experiments. (The gas-medium work, with which we originally compared our results also was not annealed before deformation.) We had to start over, therefore, in the high pressure experiments; all specimens are now ramped to temperature in a manner analogous to the one-atmosphere treatment and the cor.uparability of the two data sets now is excellent, at least for stresses greater than $25 \mathrm{MPa}$ (Meagher et al., 1991; see also Fig. 8, below). At $1100 \mathrm{~K}$, data collected at high pressure $(1 \mathrm{GPa})$ are indistinguishable from those at one atmosphere (Fig. 8a); both data sets yield the same magnitude of stress and value of $\mathbf{n}$. At $1300 \mathrm{~K}$, the high pressure data are nominally $\sim 4 \mathrm{MPa}$ stronger than the one-atmosphere data. However, our precision is $\pm \sim 2 \mathrm{MPa}$ in the high pressure machine and $\pm \sim 1 \mathrm{MPa}$ at one atmosphere and a $1 \mathrm{MPa}$ difference in strength would be predicted by the homologous temperature hypothesis or by the pressure dependence of diffusion. Therefore, it is unclear whether these small differences represent real discrepancies between the two apparatus.

The single point at $1500 \mathrm{~K}, 1 \mathrm{GPa}$, however, is $\sim 10 \mathrm{MPa}$ higher than 1-atmosphere points at $1550 \mathrm{~K}$. Either there is an error of unknown origin in this data point or there is a systematic difference between the $1 \mathrm{GPa}$ data and the 1-atmosphere data. Part of this discrepancy is in the fact that we have applied no temperature correction for the pressure effect on thermocouple emf nor have we applied a correction for differences in elastic properties at pressure. Both of these corrections will go in the right direction but both should be small and neither correction is known precisely. Fig. 8b shows that if the $10^{-4} \mathrm{sec}^{-1}$ data are plotted as $\ln \sigma \mathrm{vs} .1 / \mathrm{T}$, both sets describe straight lines, indicating a difference in $\mathbf{n}$ or a difference in $\Delta E *$. With the existing data, it is impossible to resolve these questions, but it is interesting to note that if the stress-dependence of $\mathbf{n}$ is greater at high pressure than at 1 atmosphere, the difference could disappear. For example, if $\mathbf{n}$ is 5.2 at $1500 \mathrm{~K}$, $1 \mathrm{GPa}$ rather than 5.6 at $1550 \mathrm{~K}, 1$ atmosphere, and if there are similar differences in $\mathbf{n}$ at $1300 \mathrm{~K}$, the difference shown in Fig. 8b would disappear. More data and especially data at higher pressures are necessary to sort out these differences and to enable us to test for compatibility with the homologous temperature hypothesis or the diffusion-control of creep hypothesis.

\section{SILICON}

Experiments on $\mathrm{Si}$ were conducted as described under the section on the high pressure apparatus. Specimens were $3 \mathrm{~mm}$ diameter and $7 \mathrm{~mm}$ long; Mo spacers were placed at both ends to prevent reaction with the $\mathrm{Al}_{2} \mathrm{O}_{3}$ pistons. We have not attempted one-atmosphere experiments because an extensive study by Kulkarni et al. (1980) determined that significant plasticity was introduced in polycrystalline Si only at $\mathrm{T}=0.98 \mathrm{~T} \mathrm{~m}$. Castaing et al. (1981), however, by use of high pressures (1.5 GPa), have obtained plasticity in Si single crystals at lower temperatures $(\mathrm{T} \geq$ $600 \mathrm{~K})$ than is possible at atmospheric pressure $(\mathrm{T} \geq 900 \mathrm{~K})$. They used an apparatus basically similar to HWG's machinery, but at that time the apparatus utilized an assembly with very large temperature gradients and a solid confining medium that restricted stress resolution to $\pm 50 \mathrm{MPa}$ at best. Nevertheless, they demonstrated that extensive plasticity is possible at moderate temperatures. 
Our early experiments on $\mathrm{Si}\left(\mathrm{T}>0.8 \mathrm{~T}_{\mathrm{m}}\right)$ yielded good mechanical data and showed a very strong negative pressure effect on the flow stress. We were troubled by two aspects of our results, however. Firstly, although the homologous temperature hypothesis predicts a negative pressure effect on the flow stress because of the decline of the Si melting temperature with pressure, the magnitude of the observed effect was much larger than that predicted. Secondly, we were unable to retrieve specimens intact after depressurization. The internal consistency of the mechanical data and random orientation of macroscopic fractures suggested that fracturing was occurring during decompression, but doubts remained. All of these experiments were conducted on unjacketed specimens, in large part because Si exhibits deep eutectics with all potential jacketing materials except Mo and Cr. Unfortunately, those two materials are so refractory that attempts at welding of capsules would induce extensive melting of the Si and consequent weld contamination. During the last month, however, when the new apparatus finally came on line, we conducted an experiment $(\mathrm{GB}-6)$ at $1.0 \mathrm{GPa}, 1550 \mathrm{~K}(\mathrm{~T}=0.9 \mathrm{~T} \mathrm{~m})$ in which we went to pressure and temperature over $20 \mathrm{hr}$, shortened the specimen $20 \%$ at $1 \times 10^{-4} \mathrm{sec}^{-1}$ at a steady-state flow stress of $20 \mathrm{MPa}$ and reduced $\mathrm{T}$ and $\mathrm{P}$ to ambient conditions over $6 \mathrm{hr}$. The extremely slow and delicate pressurization and depressurization procedure led to successful recovery of the complete specimen and showed that deformation had been essentially $100 \%$ by microcracking (Fig. 9). Our worst fears were confirmed, therefore, and we were back to square one with this material.

This experiment confirmed the continuation of brittle behavior to pressure in a fluid environment, but the earlier work of Castaing et al. (1981) had already demonstrated that plasticity can be induced in Si at pressure in a fluid-absent environment, even at homologous temperatures very much less than those of our experiments. As a consequence, we encapsulated a Si specimen in Co which has a eutectic of $1578 \mathrm{~K}$ with $\mathrm{Si}$ at one atmosphere and performed experiment \#GB-7 at $1.0 \mathrm{GPa}, 13 \mathrm{~J} 0 \mathrm{~K}$. The latter temperature was chosen just in case the Co-Si eutectic deepens significantly with pressure. Unfortunately, we learned the hard way that it does. During the slow ramping to the final temperature, the specimen and capsule melted suddenly and disastrously at $1285 \mathrm{~K}$, terminating the run. A second exploratory experiment in a Co capsule (GB-8) with short cycles at $1150 \mathrm{~K}$ and $1200 \mathrm{~K}$ was successful. The specimen from this experiment, still in its capsule, is shown in Fig. 9 and the mechanical data are shown in Fig. 10. Opening of the capsule revealed no evidence of cracking; the specimen is homogeneously deformed.

The data of Fig. 10 readily explain the failure by microcracking of unjacketed specimens of $\mathrm{Si}$. The very large yield drop at $1150 \mathrm{~K}$ indicates that stresses of $\sim 400 \mathrm{MPa}$ are necessary to initiate the dislocation sources that can accomodate plastic flow under these "warm" conditions $(\mathrm{T}=$ $\left.0.7 \mathrm{~T}_{\mathrm{m}}\right)$. Comparable yield drops are common in 1 -atmosphere experiments on single crystals (e.g. Alexander and Haasen, 1968) and polycrystals (Kulkarni et al., 1980). The reduction of the flow stress at $1200 \mathrm{~K}$ (after generation of these dislocation sources) suggests that at $T=0.9 \mathrm{~T}_{\mathrm{m}}$ the steady-state plastic strength of unjacketed $\mathrm{Si}$ might not be much different from that of microcracking, but a significant plastic yield stress probably also exists at that temperature, inevitably leading to initiation of microcracking first if a pressurized fluid has access to the specimen.

We chronicle these events in detail because they illustrate in a nutshell the kinds of problems that one continually encounters in performing these pioneering experiments. In the case of Si we now know that we can readily obtain high quality high pressure polycrystalline data up to $\mathrm{T} / \mathrm{T}_{\mathrm{m}}=0.75$ by encapsulation in Co. We will obtain higher temperature data on unjacketed single crystals and we will attempt heavy sputter-coating or electroplating of polycrystalline specimens with Mo or $\mathrm{Cr}$ to see if effective isolation from the confining salt is possible. 


\section{REFERENCES}

Alexander, H.\& Haasen, P. (1968) Dislocations and plastic flow in the diamond structure. Solid State Phys. 22, 27-158.

Bai, Q., Mackwell, S.J. \& Kohlstedt, D.L. (1987) The effect of oxygen fugacity and oxide activity on the creep behavior of olivine single crystals, EOS, Trans. Amer.Geophys.Union 67, 375.

Bendersky, L., Rosen, A. \& Mukherjee, A. K. (1985) Creep and dislocation substructure, International Metals Review 30, p 1.

Biberger, M. and W. Blum (1989) On the natural law of steady state creep. Scripta Metall. 23, 1419-1424.

Bowen, N.L. \& Anderson, O. (1914) The binary system MgO-SiO2, Am.J. Sci. 37, 75-89.

Borch, R.S. \& H.W. Green (1987) The homologous temperature dependence of creep in olivine: Consequences for mantle flow. Nature 330, 345-348.

Borch, R. S. \& H. W. Green (1989) Deformation of peridotite at high pressure: Comparison of traditional and homologous temperature treatments. Phys. Earth Planet Inter. 55, 269-276.

Brown, A.M. \& M.F. Ashby (1980) Correlations for diffusion constants. Acta Metall. 28 10851101.

Castaing, J., P. Veyssiere, L. P. Kubin \& J. Rabier (1981) The plastic deformation of silicon between $300^{\circ} \mathrm{C}$ and $600^{\circ} \mathrm{C}$ Phil. Mag. A44, 1407-i '13.

Chen, C.H. \& Presnall, D.C. (1975) The system $\mathrm{Mg}_{2} \mathrm{SiO}_{4}-\mathrm{SiO}_{2}$ at pressures up to 25 kilobars, Am. Mineral. 60, 398-406.

Darot, M. \& Y. Gueguen (1981) High-temperature creep of forsterite single crystals. J. Geophys. Res. 86, 6219-6234.

Demenet, J. L., J. Rabier \& H. Garem (1987) TEM observations of silicon deformed under an hydrostatic pressure. Inst. Phys. Conf. Ser. 87, 355-360.

Dorn, J. E. (1956) Some fundamental experiments on high temperature creep, in NPL Symposium, 1954, HMSO, London, 89-138.

Durham, W.B., C. Froidevaux \& O. Jaoul (1979) Transient and steady-state creep of pure forsterite at low stress. Phys. Earth. Planet. Int., 19 263-274.

Durham, W.B. \& C. Goetze (1977) A comparison of the creep properties of pure forsterite and iron bearing olivine. Tectonophysics, 40, T15-T18.

Goldstein, J. I., R. E. Hanneman, \& R. E. Ogilvie (1965) Diffusion in the Fe-Ni system at 1 atm and $40 \mathrm{Kbar}$ pressure. Trans. AIME 233, 812-820.Green, H.W. II (1985) A liquidmedium cell for piston-cylinder and Griggs Apparatus, EOS, Trans. Amer. Geophys. Union.66, 407. 
Green, H.W. \& R.S. Borch (1987) The pressure dependence of creep, Acta Metall. 28, 1051101.

Green, H. W. \& R. S. Borch (1989) A new molten salt cell for precise stress measurements at high pressure, Eur. J. Mineral., 1, 213-219.

Green, H. W. \& R. S. Borch (1990) High pressure and temperature deformation experiments in a liquid confining medium. Geophys. Monog. 56, 195-200.

Harvey, P.J. \& Hoodless, I.M. (1967) Self-diffusion and ionic conductivity in single crystals of caesium chloride, Phil. Mag. 16, 543-551.

Heard, H. C. \& S. H. Kirby (1981) Activation volume for steady-state creep in polycrystalline $\mathrm{CsCl}$ : cesium chloride structure. In: Mechanical behavior of crustal rocks, Geophys. Mono 24, 83-91.American Geophysical Union,

Jaoul, O. (1990) Multicomponent diffusion and creep in olivine. J. Geophys. Res. 95, 1763117642.

Karashima, S., H. Oikawa \& T. Motomiya (1969) Trans. Japan Inst. Metals 10, 205.

Kulkarni, S.B., Lall, C. Pope, D.P. \& Graham, C.D., Jr. (1980) The deformation of silicon at high temperatures and strain rates, Met. Trans 11A, 1869-1876.

Luton, M. J. \& C. M. Sellars (1969) Dynamic recrystallization in nickel and nickel-iron alloys. Acta Metall. 17, 1033-1043.

Meagher, S., R. Borch, H. W. Green \& A. K. Mukherjee (1991) The pressure dependence of creep in nickel. TMS (in press)

Mecking, H. Nicholas, B. Zarubova, N. \& Kocks, U.F. (1986) A "universal" temperature scale for plastic flow, Acta Metall. 34, 527-535.

Mukherjee, A. K., (1975) High temperature creep, treatise on Materials Science and Technology, 6, p. 163-224, R-J. Arsenault, Editor, Academic Press, New York.

Mukherjee, A.K., Bird, J.E. \& Dorn, J.E. (1969) Experimental correlations for high-temper-ature creep, Trans. Amer. Soc. Metals 62, 155-159.

Nachtrieb, N.H., Resing, H.A. \& Rice, S.A. (1959) Effect of pressure on self-diffusion in lead, J. Chem. Phys. 31, 135-138.

Norman, E. C. \& S. A. Duran (1970) Steady-state creep of pure polycrystalline nickel from 0.3 to $0.55 \mathrm{~T}_{\mathrm{m}}$. Acta Metall. 18, 723-731.

Poirier, J.P. (1978) is power-law creep diffusion controlled? Acta Metall. 26, 629-637.

Ricoult, D.L. \& Kohlstedt, D.L. (1985) Experimental evidence for the effect of chemical environment upon the creep rate of olivine, in Shock, R.N. (ed.) Point Defects in Minerals. Geophys. Monogr. Ser. 31 Amer. Geophys. Union, Wash. D.C., pp. 171-184.

Ruano, O.A. \& Sherby, O.D. (1987) On constitutive equations for various diffusion-controlled creep mechanisms. Rev. Physique Appliquees; Additions de Physique. 
Sellars, C.M. (1978) Recrystallization of metals during hot deformation, Phil. Trans. R. Soc. Land. A288, 147-158.

Siethoff, H. (1983) Cross-slip in high-temperature deformation of germanium, silicon and indium antimonide, Phil. Mag. A. 47, 657-669.

Sherby, O.D. \& Simnad, M.T. (1961) Predictions of atomic mobility in metallic systems, Trans. Am.Soc. Met. 54, 227-240.

Sherby, O.D. \& Weertman, J. (1979) Diffusion-controlled dislocation creep: A defense, Acta Metall. 27, 387-400.

Smyth, D.M. \& Stocker, R.L. (1975) Point defects and non-stoichiometry in forsterite, Phys. Earth Planet. Int. 10, 183-192.

Straub,S. \& W. Blum (1990) Does the "natural" third power law of steady state creep hold for pure aluminium: (in press).

Weertman, J. (1970) The creep strength of the earth's mantle, Rev. Geophys. Space Phys. 8, 145-168.

Weertman, J. \& J. J. Weertman (1987) Constitutive equations and diffusion-dislocation controlled creep. Proc. 8th Riso Symp. on Metall. and Mater. Sci., S. I. Anderson et al., eds., 191203. 


\section{FIGURE CAPTIONS}

Fig. 1. Cross section of high pressure assembly. The specimen is $3 \mathrm{~mm}$ diameter. For experiments in this study the following modifications are made:

A. The metal sleeve labeled $\mathrm{Ni}$ may be $\mathrm{Ni}, \mathrm{Co}$, or Mo, depending on the chemical environment required by the specimen or capsule material.

B. The Pt specimen jacket is not utilized for Ni or Ag experiments; it is replaced by Co for Si experiments.

C. The unlabeled, dark gray, region around the specimen and the lighter gray region around the $\mathrm{Al}_{2} \mathrm{O}_{3}$ piston are made of salts of the quaternary $\mathrm{Ba}-\mathrm{Ca}-\mathrm{K}-\mathrm{Na}-\mathrm{Cl}$ system which are molten under experimental conditions.

D. Specimens in many experiments are shorter; for that case, the two thermocouples (tc) are placed at the same height in the center of the specimen.

Fig. 2. Photographs of $\mathrm{Ni}$ specimens.

A. Specimens before and after deformation at one atmosphere in the molten salt. Scale labeled in $\mathrm{cm}$.

B. \& C. Cross sections of specimens deformed at one atmosphere pressure, $1300 \mathrm{~K}$ and $1100 \mathrm{~K}$, respectively. Scale divisions in $\mathrm{mm}$.

D. Specimens before and after deformation at $1 \mathrm{GPa}$ pressure in molten salt. Undeformed specimen is $3 \mathrm{~mm}$ diameter.

Fig. 3. $5 \mathrm{GPa}$ apparatus. Presssure vessel is located just above the base (with thermocouple wires extending beneath it). An identical $3 \mathrm{GPa}$ vessel to the right shows the pressure and deformation pistons protruding from the core of the vessel. The larger $5 \mathrm{GPa}$ vessel is shown on edge behind the $3 \mathrm{GPa}$ vessel. Swiss Army Knife for scale is $6 \mathrm{~cm}$ long.

Fig. 4. TEM micrographs of Ni starting material.

A.\& B. Cold-worked microstructures of as-received rod.

C.\& D. Partially recrystallized microstructure of specimen ramped to $800 \mathrm{~K}$ at $1.5 \mathrm{~K} / \mathrm{min}$ and quenched. Specimens ramped to higher temperatures are fully recrystallized to strain-free aggregates.

Fig. 5. Stress-strain plots for representative one-atmosphere experiments.

A.\&B. Strain-rate stepping experiments at $1300 \mathrm{~K}\left(0.75 \mathrm{~T}_{\mathrm{m}}\right)$ and $1550 \mathrm{~K}\left(0.9 \mathrm{~T}_{\mathrm{m}}\right)$ for determination of $\mathbf{n}$. Note oscillations due to periodic recrystallization.

C. Two experiments deformed at $1010 \mathrm{~K}$ showing reproducibility of results for specimens that have been preannealed at $1550 \mathrm{~K}$ and ramped to temperature at $1.5 \mathrm{~K} / \mathrm{min}$.

D. Comparison of strain-rate stepping experiments with those performed at a single, constant, strain rate. Maximum disagreement is $3 \mathrm{MPa}$.

Fig. 6. Ln stress vs. In strain-rate plot of steady-state flow stresses for one-atmosphere experiments showing decrease of $\mathbf{n}$ with increasing temperature (and therefore decreasing stress).

Fig. 7. Normalized ln stress vs. 1/T diagram for one-atmosphere data showing reproducibility and internal consistency of results. Slope of line gives $\Delta \mathrm{E}_{\mathrm{C}^{*}}=290 \mathrm{KJ} / \mathrm{mole}$, in agreement with published values of $\triangle \mathrm{E}_{\mathrm{D}}{ }^{*}$. 
Fig. 8. Comparison of steady-state flow stresses for experiments at one-atmosphere (open symbols) and at 10,000 atmospheres $(1 \mathrm{GPa}$ ) pressure (solid symbols). Data collected at $1100 \mathrm{~K}$ are represented by triangles, those at $1300 \mathrm{~K}$ by squares, at $1500 \mathrm{~K}$ by a hexagon, and at $1550 \mathrm{~K}$ by diamonds.

A. Plot of stress vs. strain rate. Data at $1100 \mathrm{~K}$ are in excellent agreement; those at $1300 \mathrm{~K}$ differ by $\sim 4 \mathrm{MPa}$ and are within experimental error. However, the sole point at $1500 \mathrm{~K}, 1 \mathrm{GPa}$ may signify that $\mathbf{n}$ is pressure dependent. See text for discussion.

B. Plot of $10^{-4} \mathrm{sec}^{-1}$ data in a ln $\sigma$ vs. $1 / \mathrm{T}$ plot. Both data sets plot as straight lines suggesting that either $\mathbf{n}$ or $\Delta E^{*}$ is pressure dependent. See text for discussion.

Fig. 9. Photographs of Si specimens contrasting the starting material (left) with the behavior of unjacketed material at $1500 \mathrm{~K}, 1 \mathrm{GPa}\left(0.9 \mathrm{~T}_{\mathrm{m}}\right)$ (center) and a specimen jacketed in Co at $1200 \mathrm{~K}, 1$ $\mathrm{GPa}\left(0.75 \mathrm{~T}_{\mathrm{m}}\right)$ (right). The microcracking that dominates unjacketed deformation even at very high homologous temperature is completely eliminated by encapsulation. The lump on the lower right of the right-hand specimen is a wrinkle that developed in the capsule; sectioning of the specimen revealed no fractures.

Fig. 10. Stress-strain curves for the Co-jacketed specimen of Fig. 9. The low apparent modulus of the "elastic" portion of these curves is a result of flow of the Co end caps during loading. The stronger curve is cycle \#1 at $1150 \mathrm{~K}$; the weaker is cycle \#2 at $1200 \mathrm{~K}$.

Fig. 11. (a) Phase relations in the system $\mathrm{MgO}-\mathrm{SiO}_{2}$ at $0.1 \mathrm{MPa}$. The intermediate phase, forsterite $\left(\mathrm{Mg}_{2} \mathrm{SiO}_{4}\right)$, is bounded by a eutectic and peritectic on the $\mathrm{MgO}$ - and $\mathrm{SiO}_{2-}$ excess sides respectively, with solidus temperature differences of $40 \mathrm{~K}$ on the $\mathrm{MgO}$ side and $330 \mathrm{~K}$ on the $\mathrm{SiO}_{2}$ side (From Bowen and Anderson, 1914) (b) Pressure dependence of melting for the system $\mathrm{Mg}_{2} \mathrm{SiO}_{4}-\mathrm{SiO}_{2}$. Above $\sim 140 \mathrm{MPa}, \mathrm{MgSiO}_{3}$ melts congruently. (From Chen and Presnall, 1.975).

Fig. 12. Hypothetical melting relations in a binary eutectic system with solid solution for a polycrystal composed primarily of, and therefore mechanically dominated by, phase $\alpha_{\mathrm{ss}}$ but with $\beta_{\text {ss }}$ present in excess of the maximum potential solubility (as for composition $X$ ). The amount of solid solution is exaggerated for clarity. The assumption in this model is that the appropriate melting temperature for normalization is that at which the equilibrium $\alpha_{S S}$ of the experimental temperature is stable with a melt (as discussed by Weertman, 1970). For example, for bulk composition $X_{4}$ at $T_{1}$, the appropriate melting temperature would be $T_{m 1}$ (circles); for $T_{2}$ (squares), the melting temperature would be $\mathrm{T}_{\mathrm{m} 2}$, etc. The melting temperature would then be a function of both pressure and temperature, but would be independent of bulk composition. Above the eutectic ternperature, the homologous temperature would be constant (equal to 1), and hence the flow stress would be constant with increasing temperature until sufficient melt were generated to mechanically affect creep. 


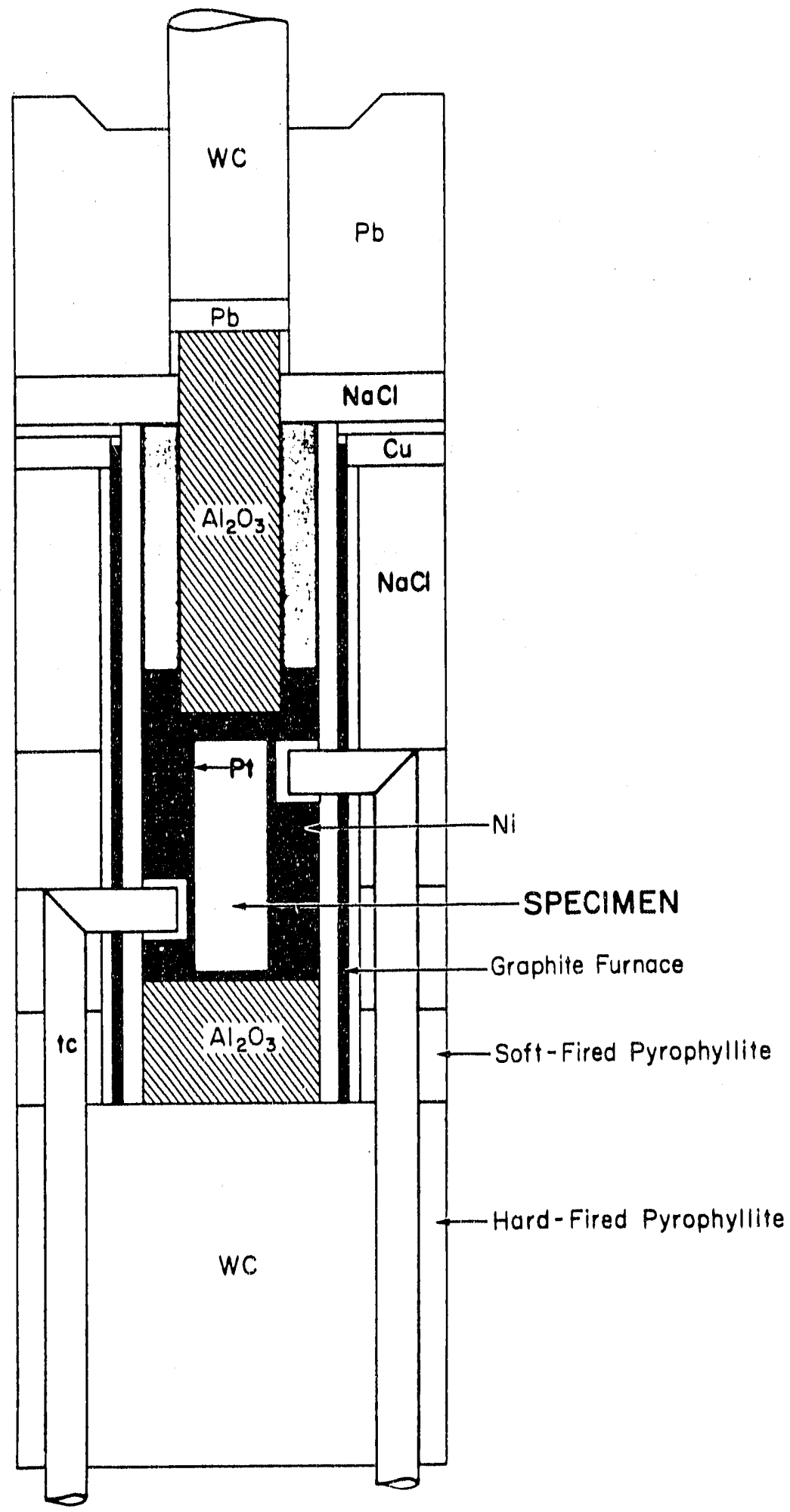



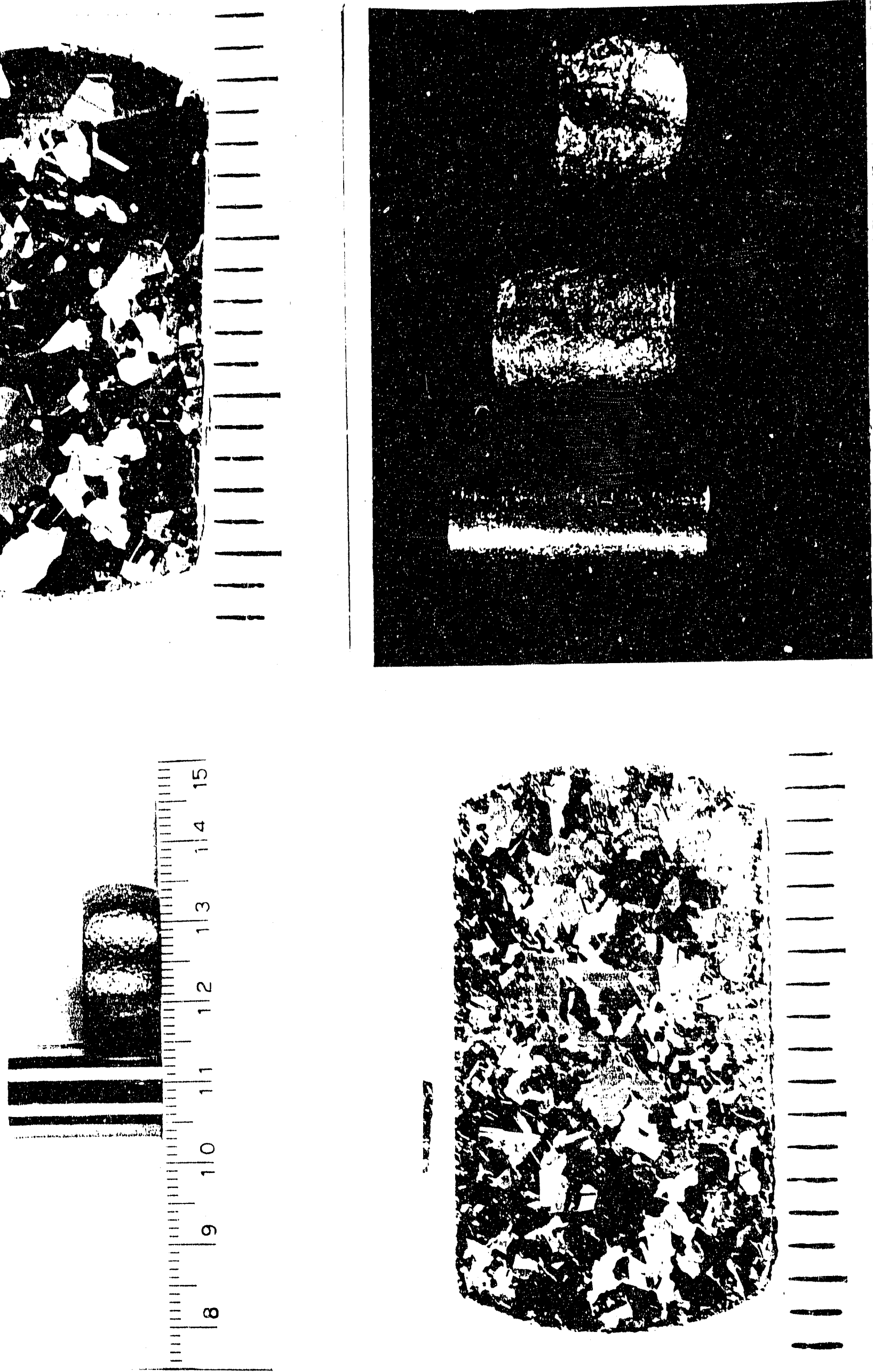

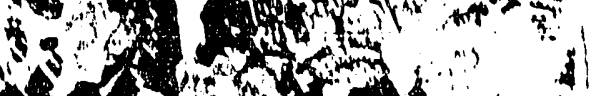

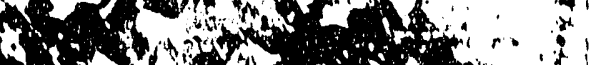
2.

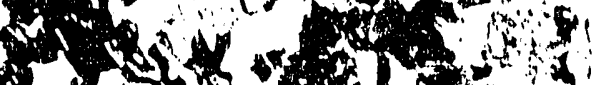

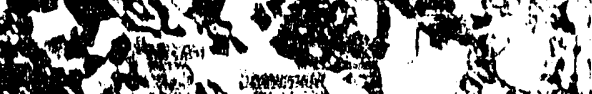
$30 x+2 x+4$

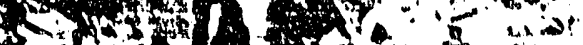

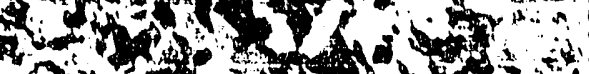
Dy $-5-4,1-1$

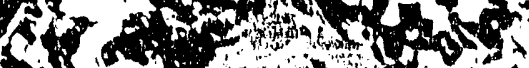

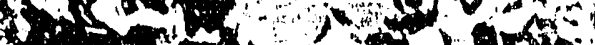

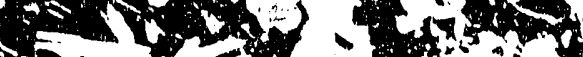

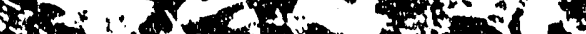

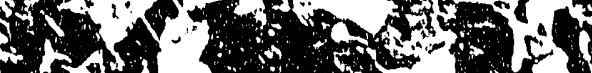

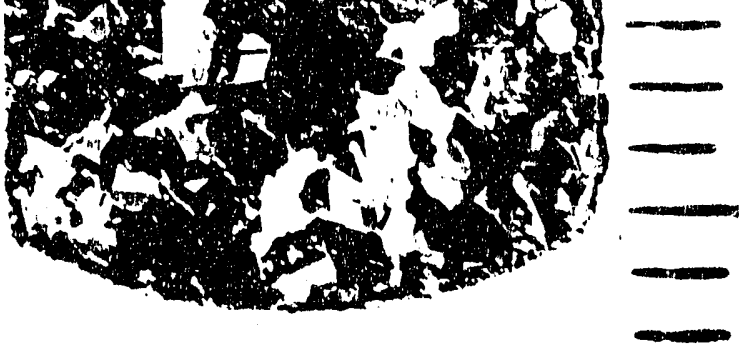




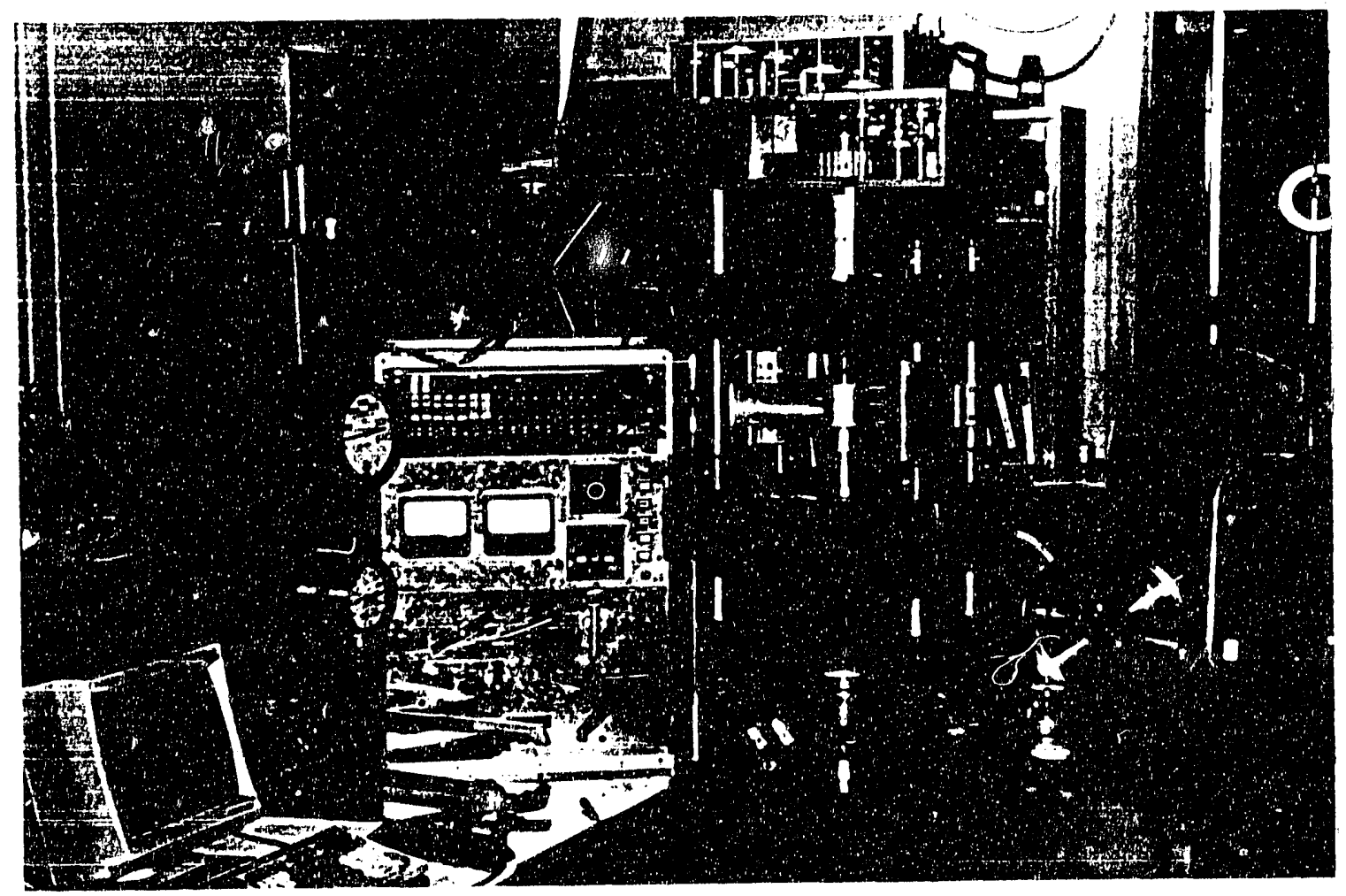



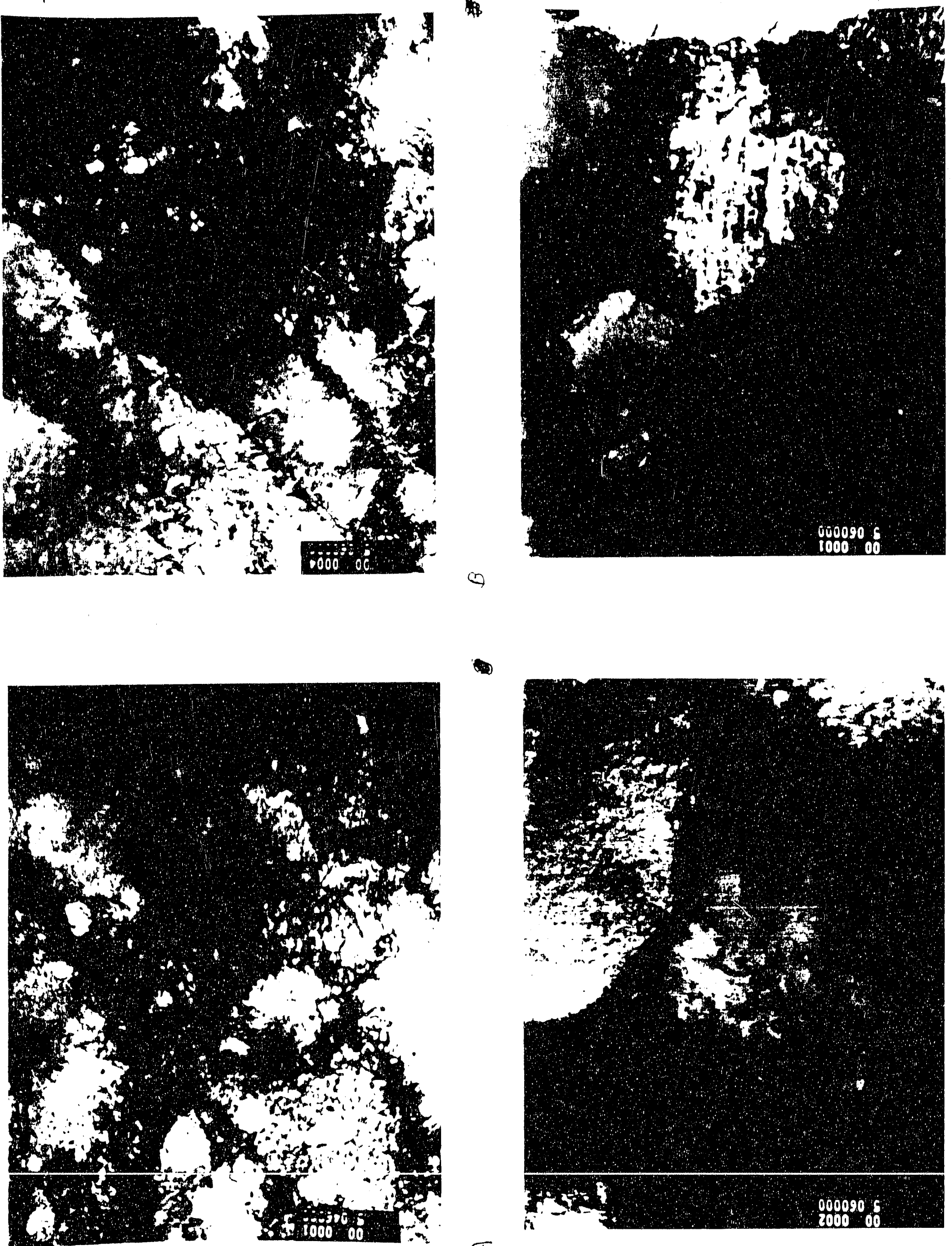

b

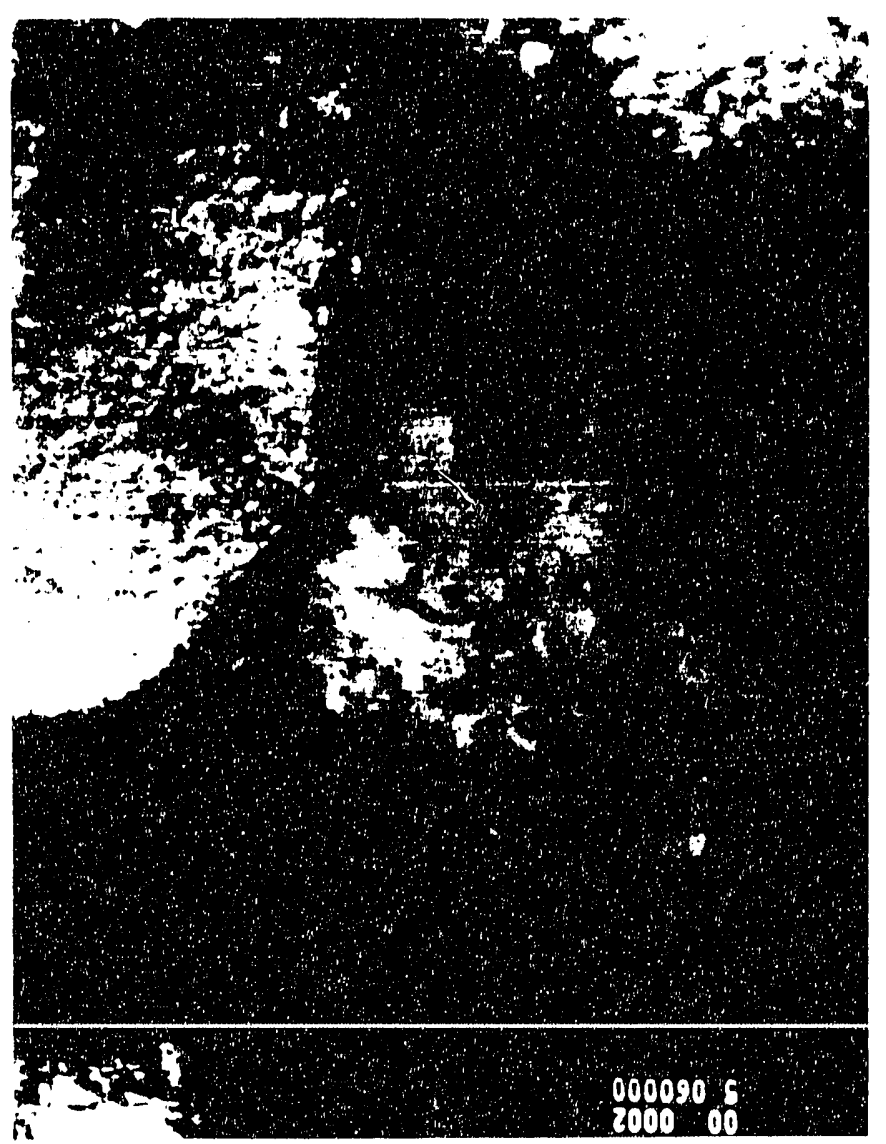




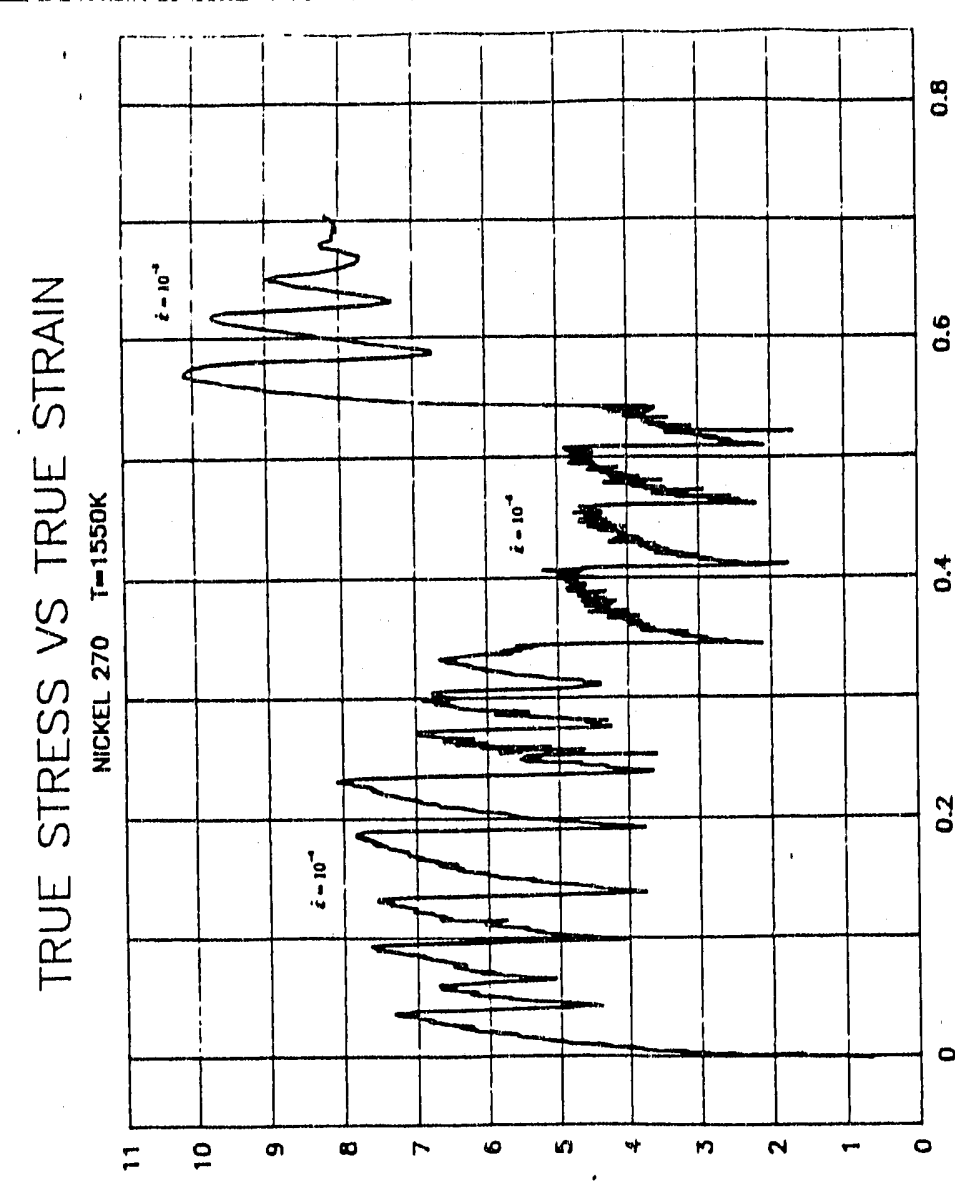

(*uo!IIIN)

(od) Ss3als 3nख4

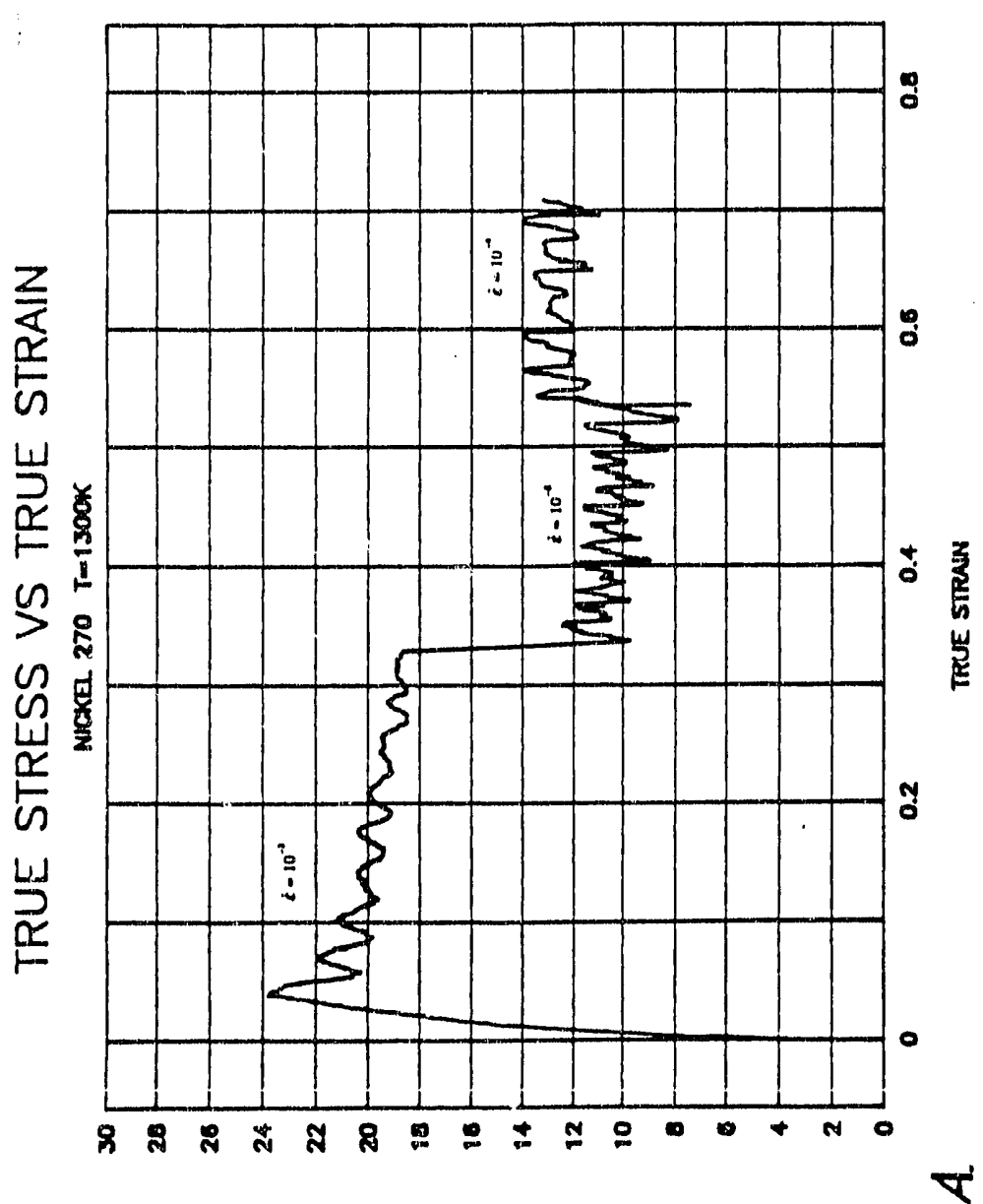

(avolinin)

Fig. 5

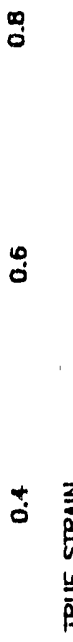

ำ

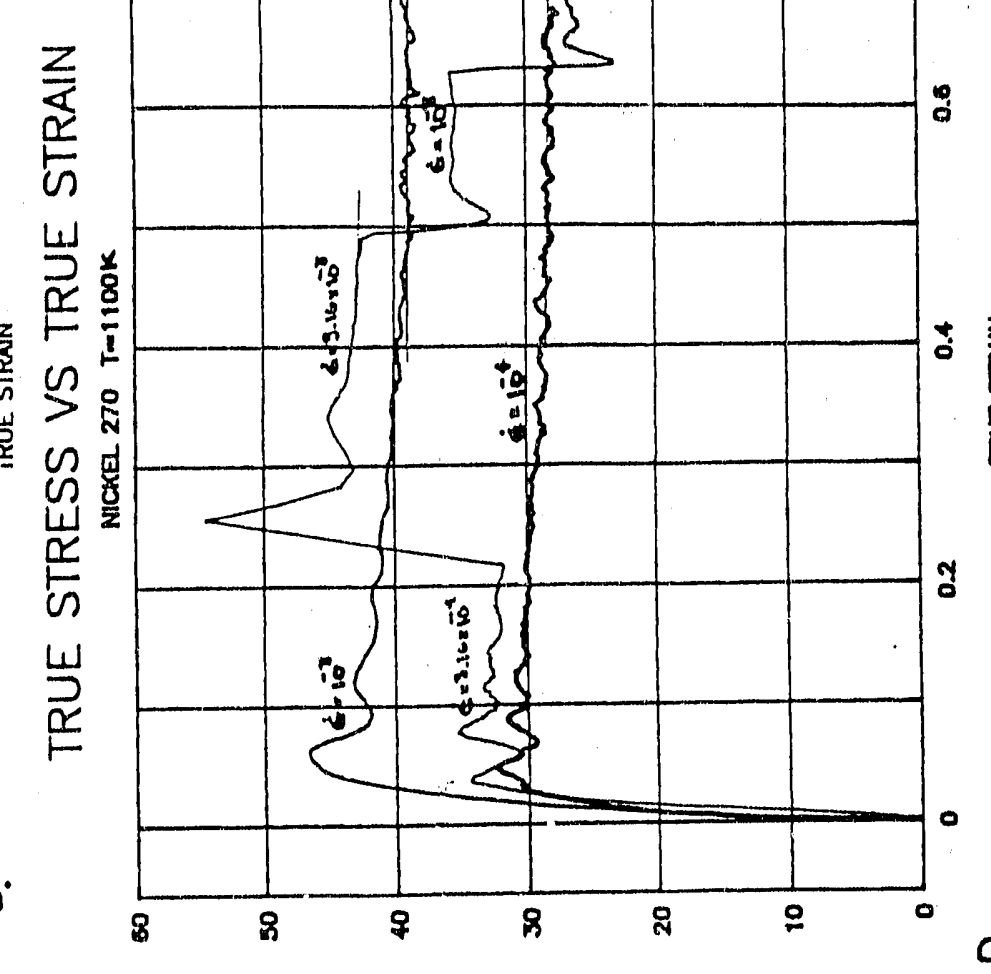

(auollitw)

(Dd) scauts 3 and 
Nickel 270

Compression Testing

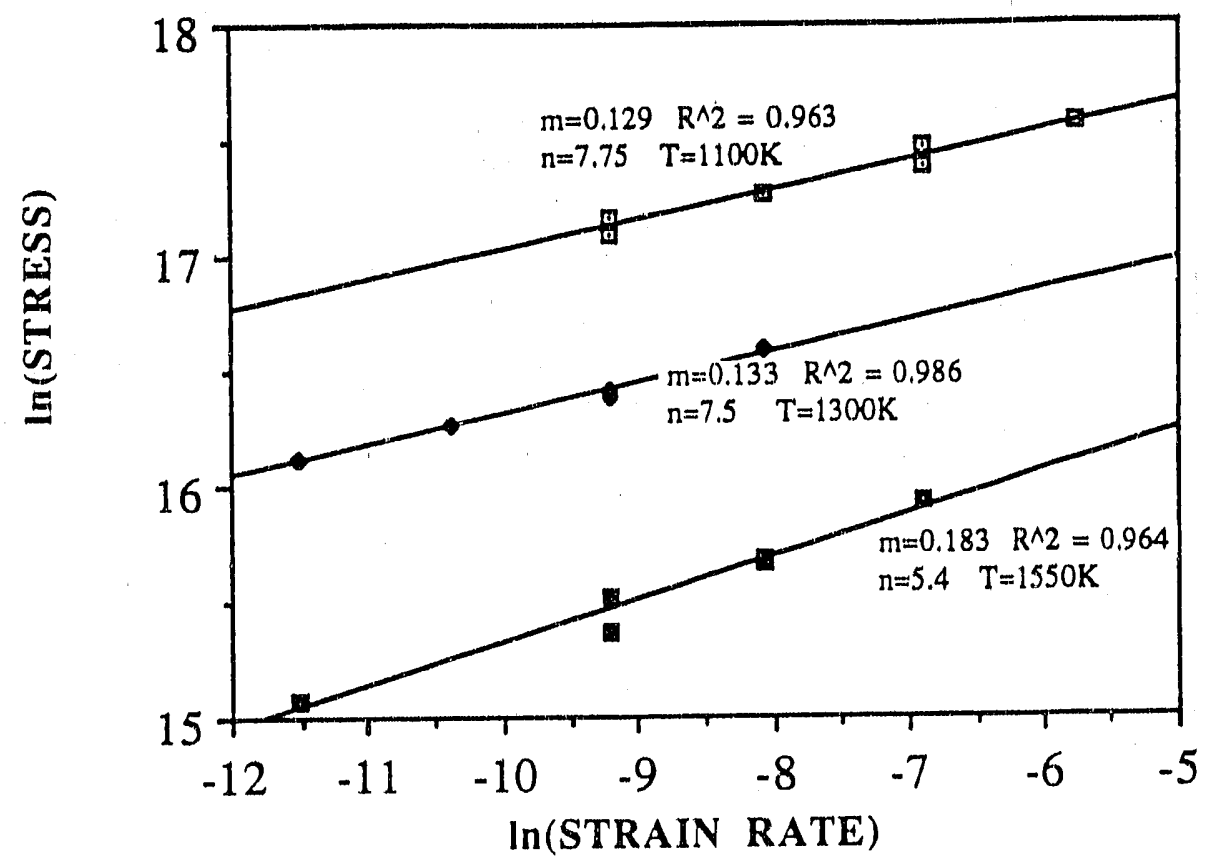

a. $T=1100 \mathrm{~K}$

- $T=1300 \mathrm{~K}$

- $T=1550 \mathrm{~K}$

F.g. 6

ACTIVATION ENEGRY

NICKEL $270 \quad 0.55-0.90 \mathrm{Tm}$

\begin{tabular}{l}
$E$ \\
5 \\
0 \\
0 \\
0 \\
\hline \\
\hline
\end{tabular}

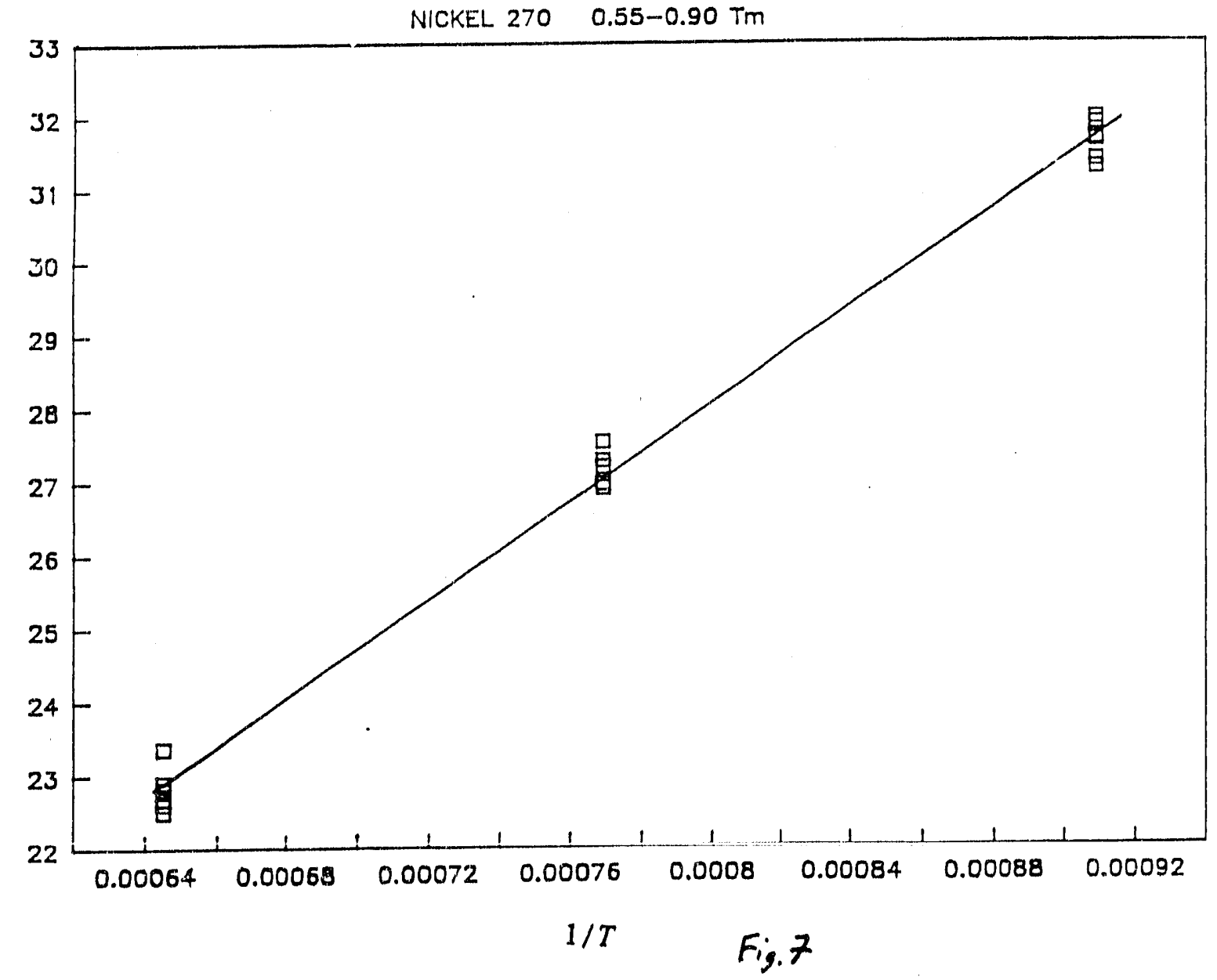


Nickel 270

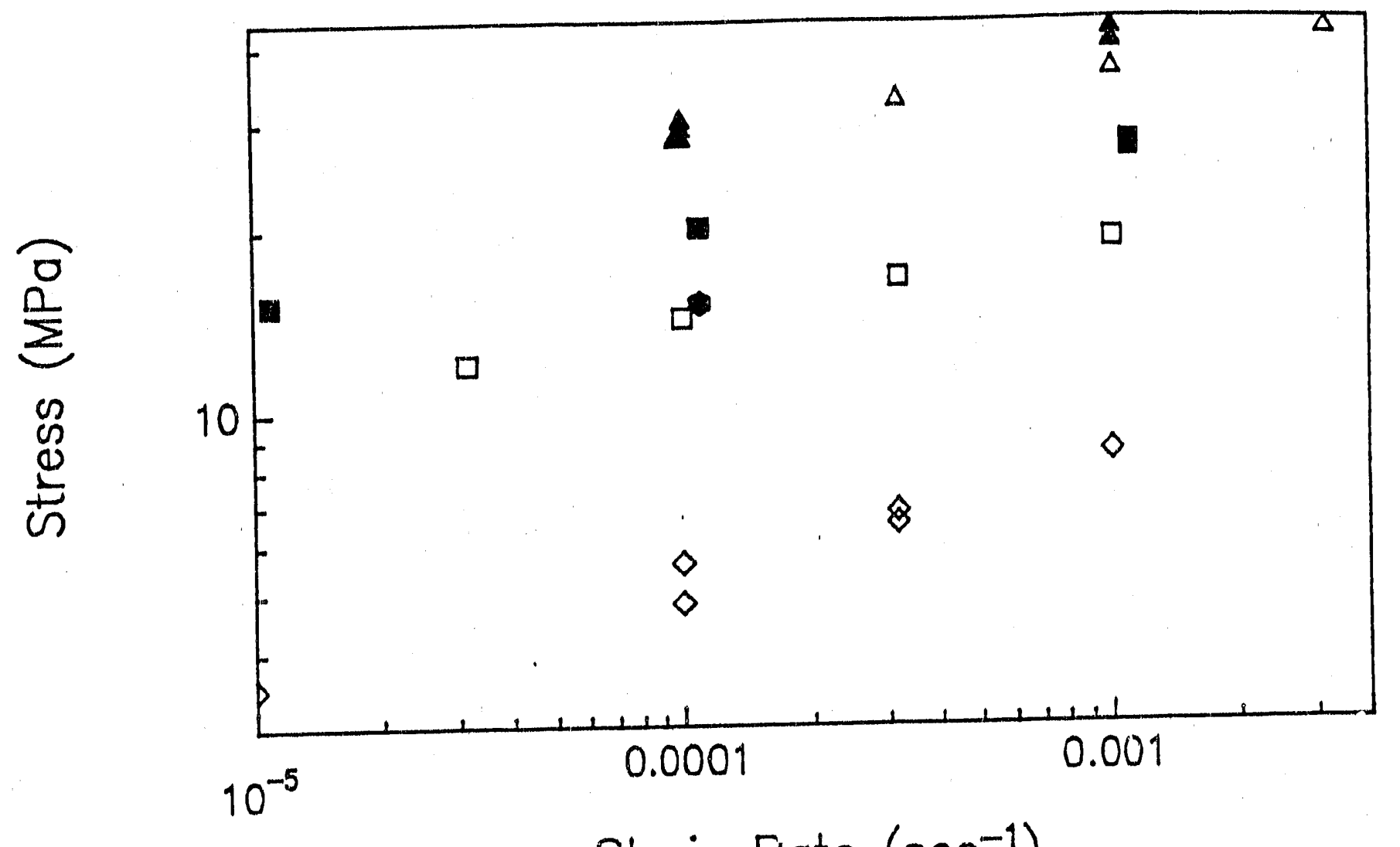

(a)

$$
\dot{\varepsilon}=1 \times 10^{-4} \mathrm{sec}^{-1}
$$

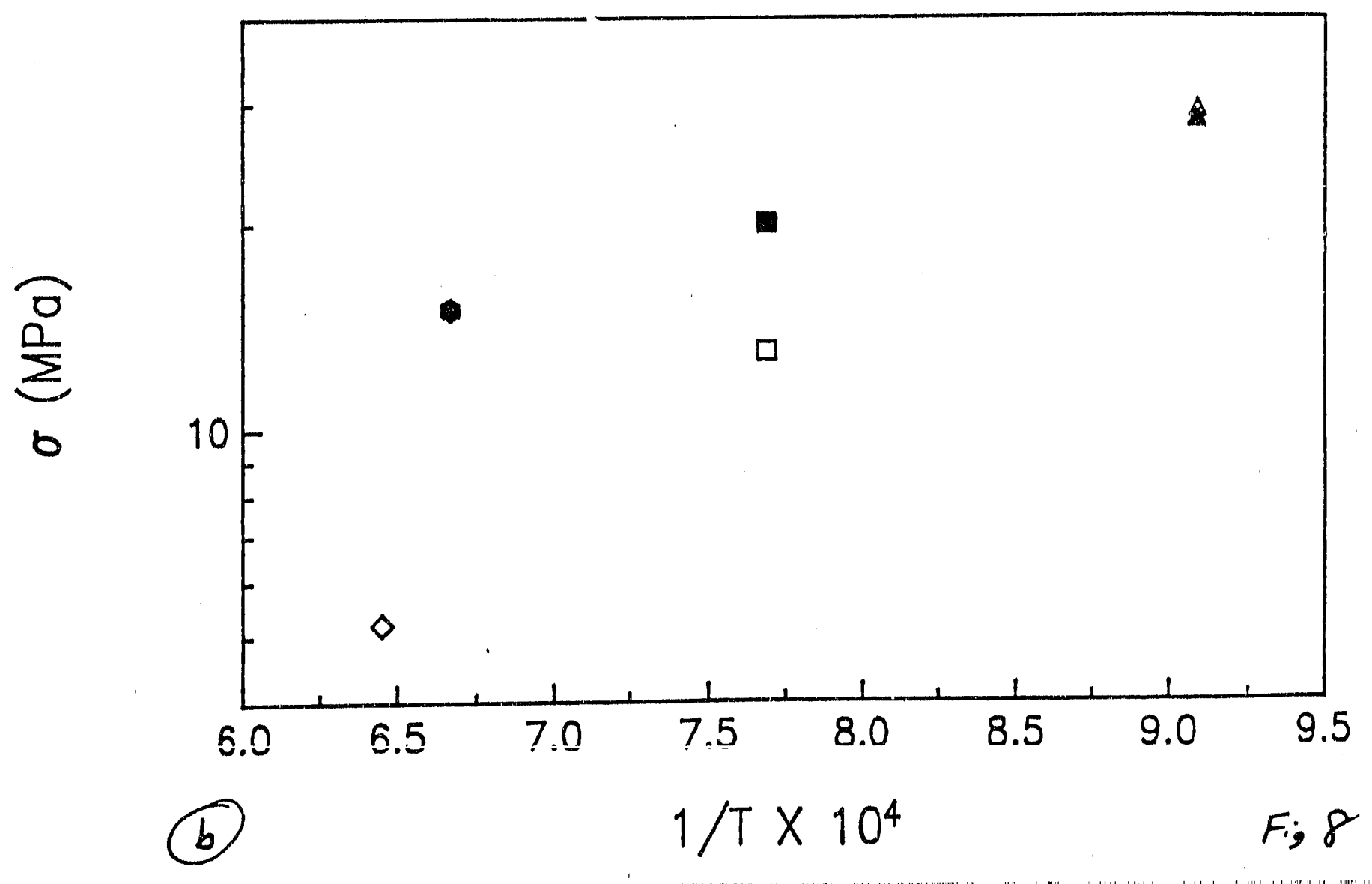




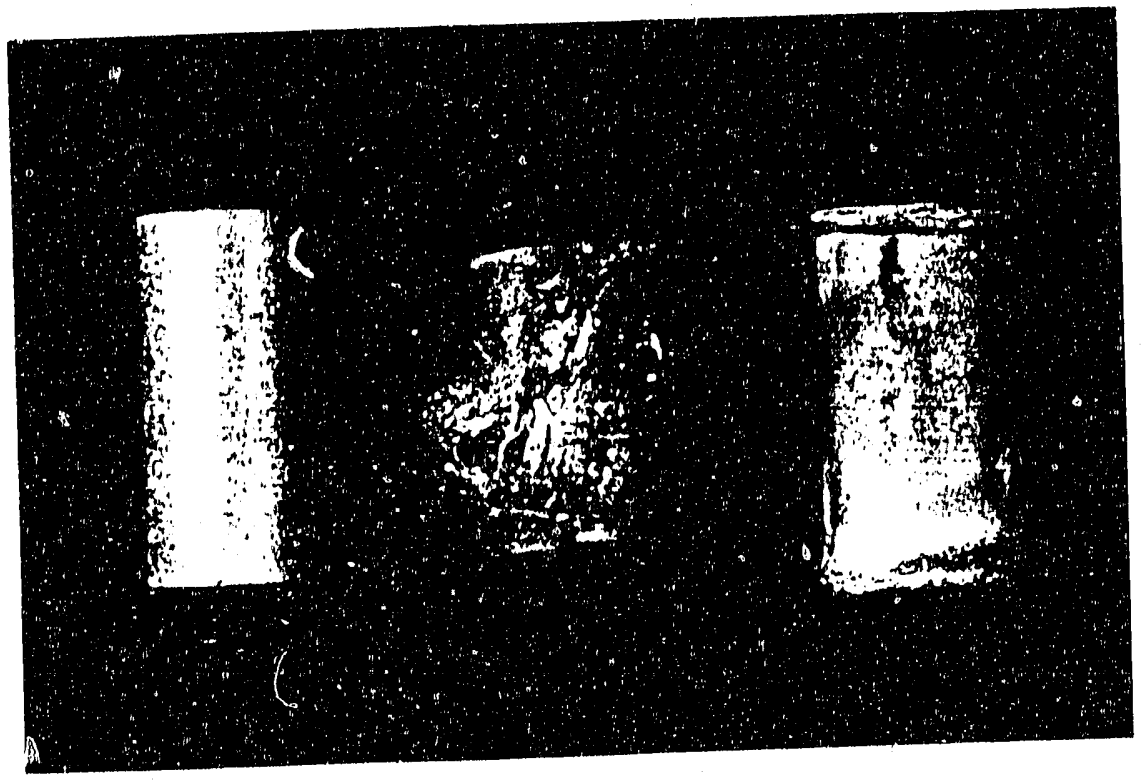




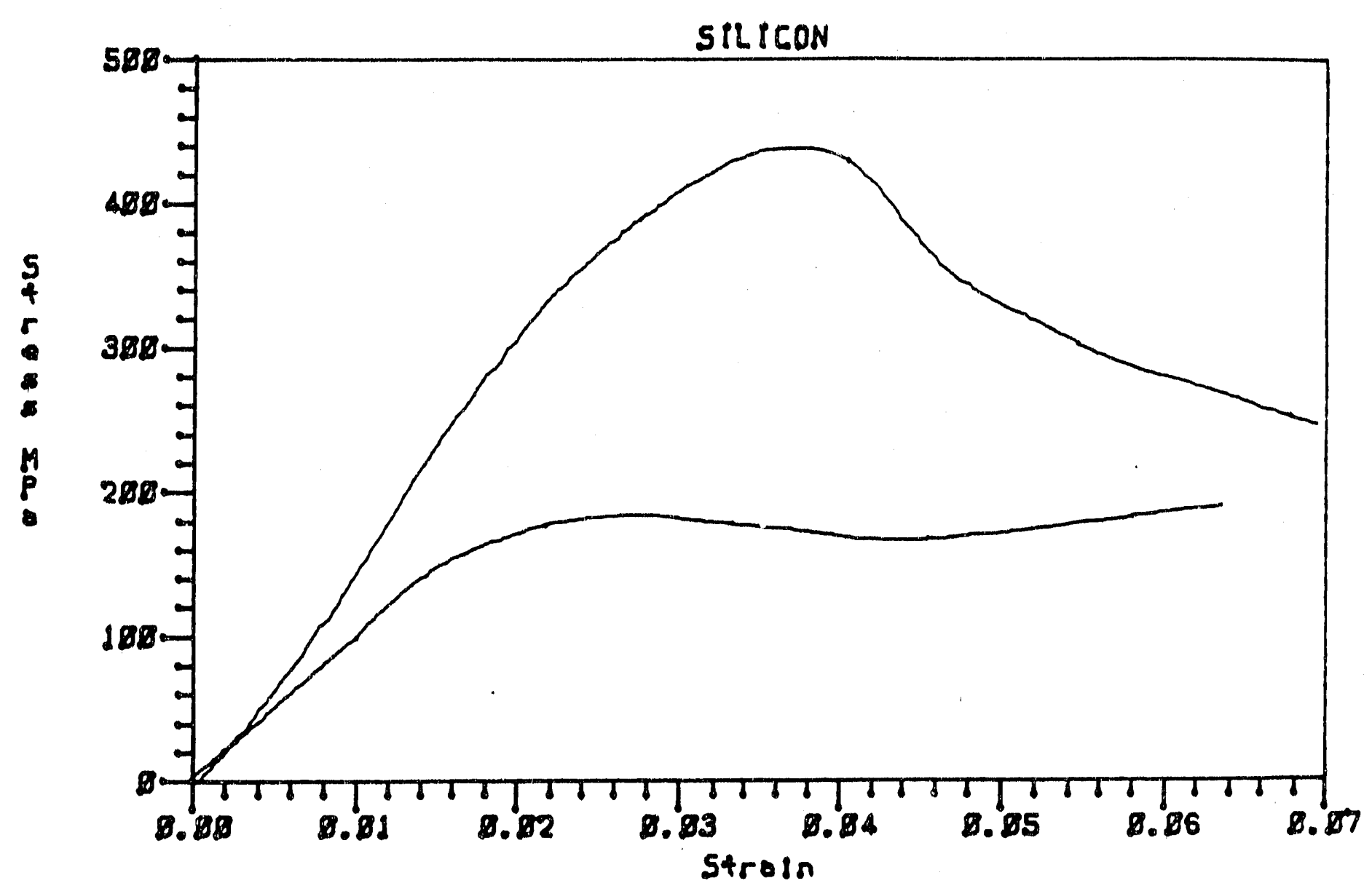

Fig. 10 


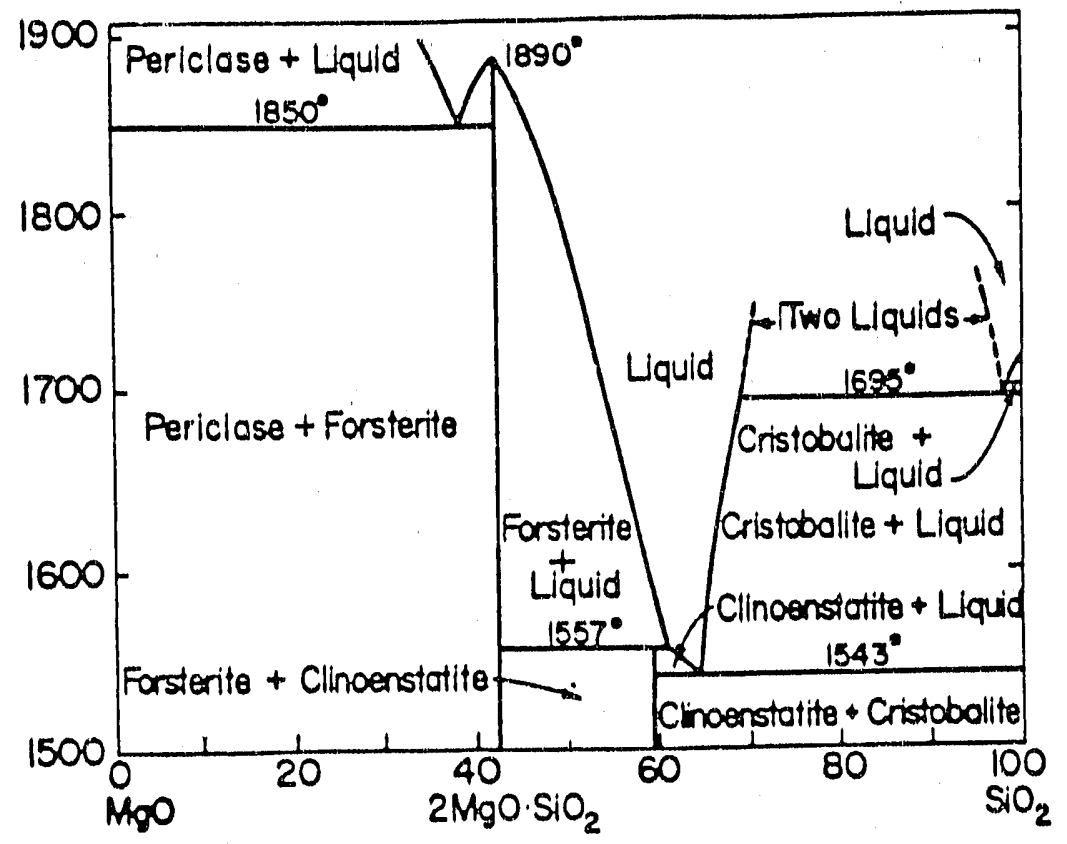

Fig. $11 \mathrm{a}$

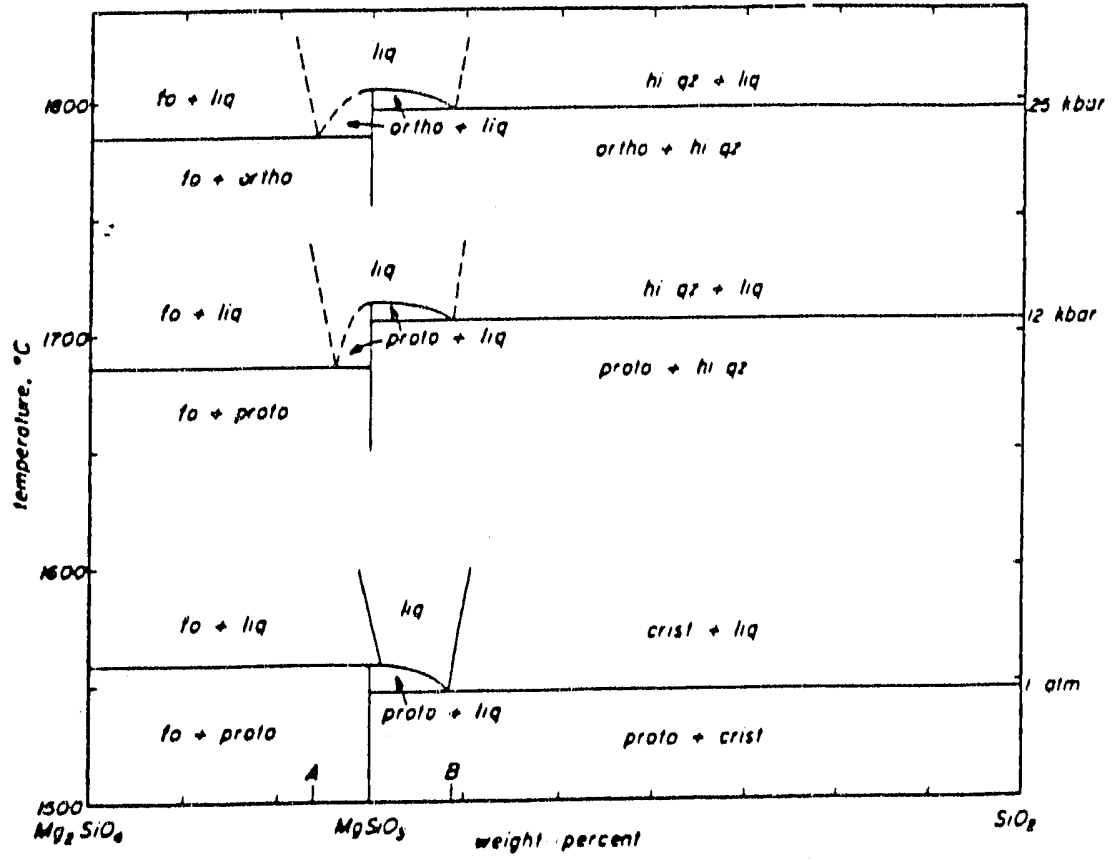

Fig. $11 b$ 


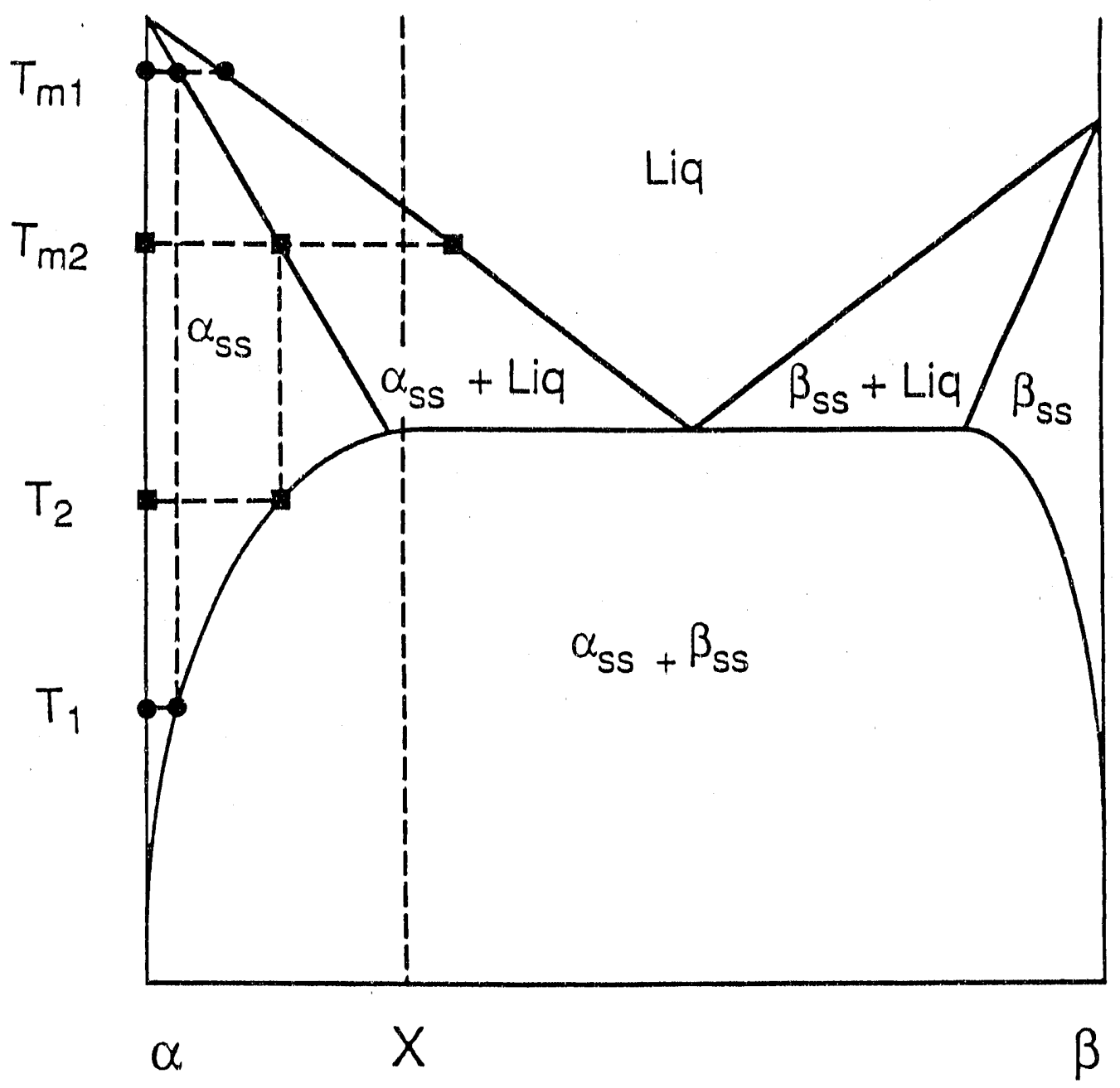

Fig 12

\section{DISCLAIMER}

This report was prepared as an account of work sponsored by an agency of the United States Government. Neither the United States Government nor any agency thereof, nor any of their employees, makes any warranty, express or implied, or assumes any legal liability or responsibility for the accuracy, completeness, or usefulness of any information, apparatus, product, or process disclosed, or represents that its use would not iniringe privately owned rights. Reference herein to any specific commercial product, process, or service by trade name, trademark, manufacturer, or otherwise does not necessarily constitute or imply its endorsement, recommendation, or favoring by the United States Government or any agency thereof. The views and opinions of authors expressed herein do not necessarily state or reflect those of the United States Government or any agency thereof. 

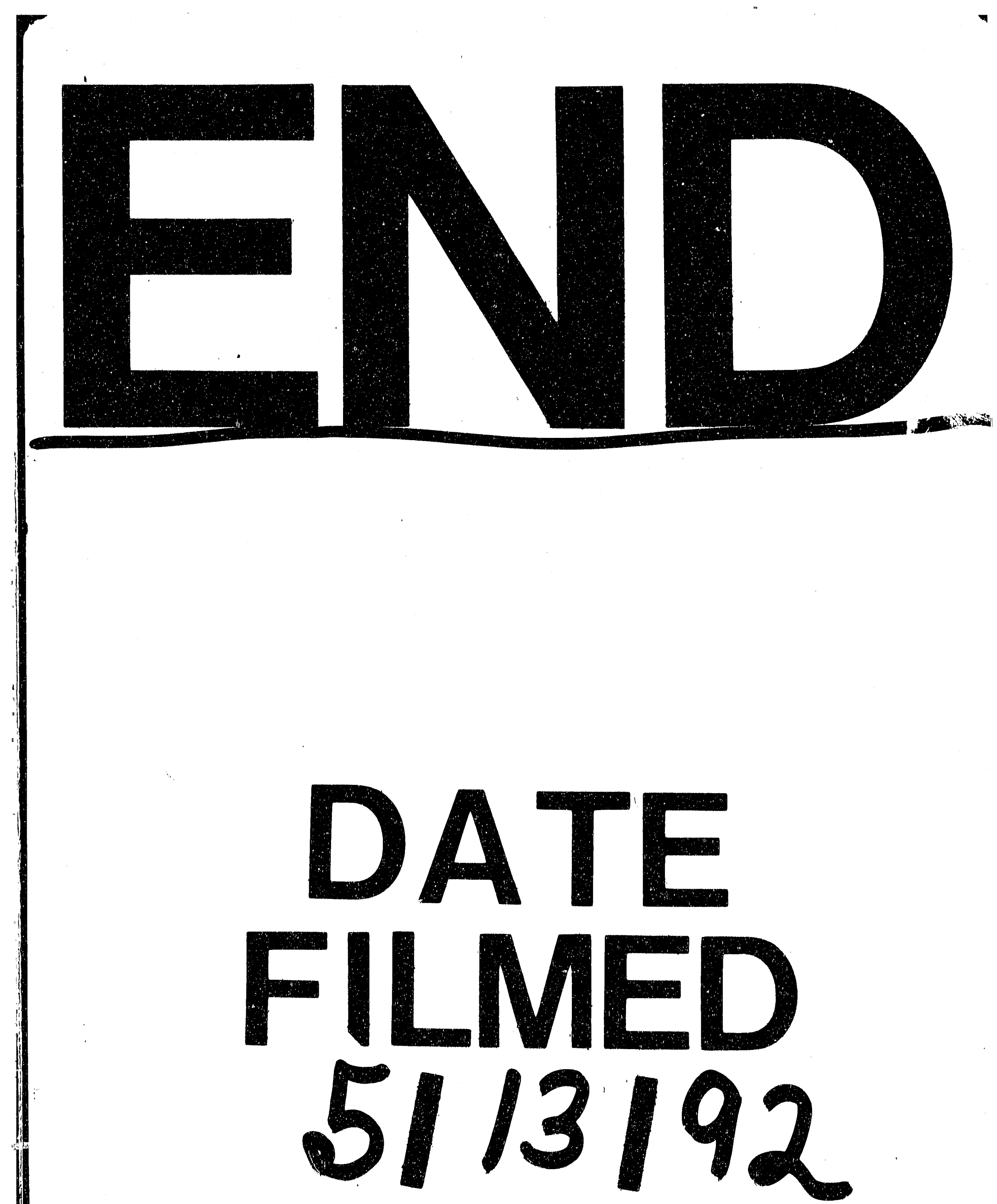
